\title{
EXPLORING THE RELATIONSHIPS BETWEEN K-POP FANS' IDENTITIES AND MEDIA CONSUMPTION IN WEB 2.0 ERA
}

\author{
A Thesis \\ presented to \\ the Faculty of the Graduate School \\ at the University of Missouri-Columbia \\ In Partial Fulfillment \\ of the Requirements for the Degree \\ Master of Arts \\ by \\ ZIXUAN ZHAO \\ Dr. Shuhua Zhou, Thesis Supervisor
}

MAY 2021 
The undersigned, appointed by the dean of the Graduate School, have examined the thesis entitled

\section{EXPLORING THE RELATIONSHIPS BETWEEN K-POP FANS’ IDENTITIES AND}

\section{MEDIA CONSUMPTION IN WEB 2.0 ERA}

presented by Zixuan Zhao,

a candidate for the degree of master of arts,

and hereby certify that, in their opinion, it is worthy of acceptance.

Professor Shuhua Zhou

Professor Sungkyoung Lee

Professor Amanda Hinnant 


\section{ACKNOWLEDGMENTS}

First of all, I would like to express my deepest appreciation to my thesis chair, Dr. Shuhua Zhou, who inspired my passion for communication research since my very first course at graduate school. Without his insightful guidance and encouragement, this thesis would not have been possible.

I also would like to extend my gratitude to my committee members, Dr. Sungkyoung Lee, who guided me into media psychology research and taught me quantitative method. Her expertise and visions have helped me carried out my thesis research immeasurably. I must also thank Dr. Amanda Hinnant for her kind support and professional guidance throughout my graduate study, her media sociology course has provided me a lot of inspiration for my thesis from a sociology perspective.

Special thanks to my dad Yikun Zhao, a professor of music, who provided me with

invaluable passion for developing my research ideas. Thanks to my mom and my friend Hanwen for their emotional support. 


\section{TABLE OF CONTENTS}

ACKNOWLEDGMENTS................................................... ii

LIST OF TABLES $\quad$......................................................

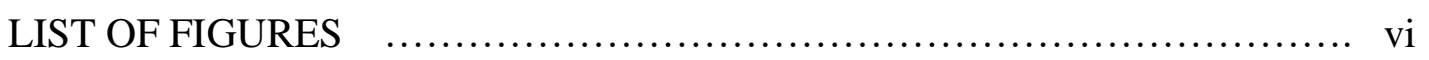

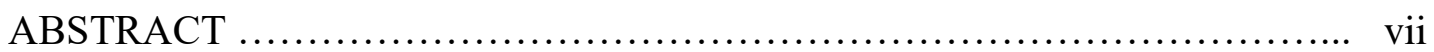

CHAPTER

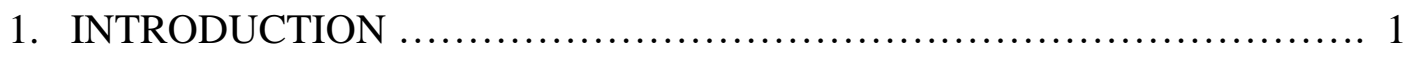

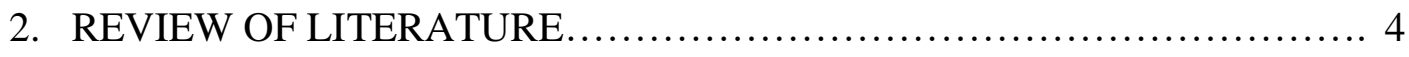

2.1 Social identity theory and self-categorization theory .................... 4

2.2 Two aspects of fan identification......................................... 9

2.3 Fan motivations ....................................................... 10

2.4 K-pop user-generated content and participatory culture ................... 12

2.5 Types of K-pop UGC on YouTube ..................................... 15

2.6 Research questions and hypotheses .................................. 18

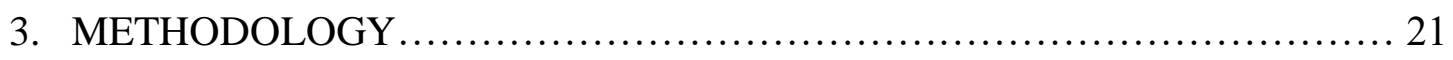

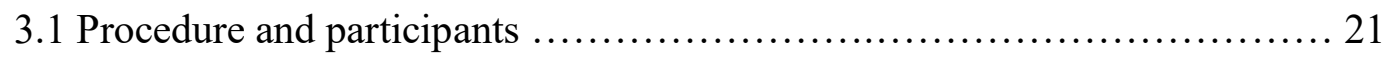

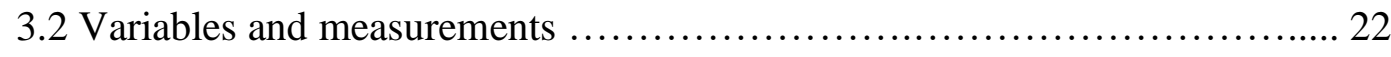

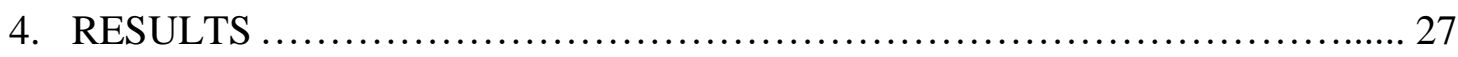

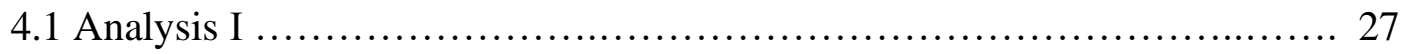

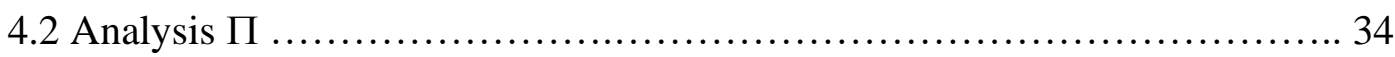

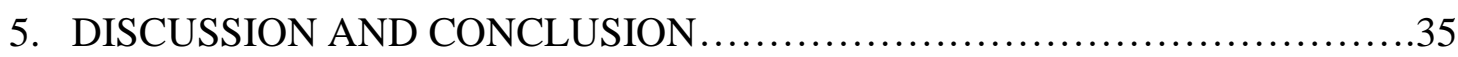

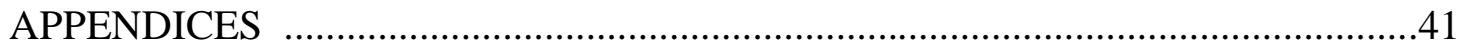

A. Top 10 Twitter Best Fandoms ........................................41 


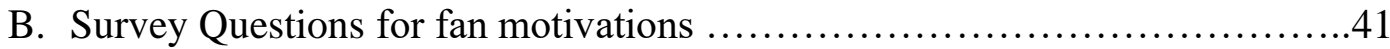

C. Survey Questions for fanship level ...............................43

D. Survey Questions for fan community identification ....................44

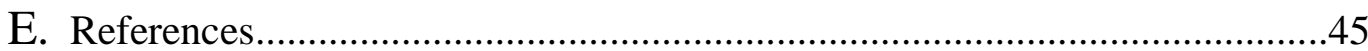




\section{LIST OF TABLES}

Table Page

2.1 Genre classification for K-pop videos on YouTube .19

3.1 Reliability of Measurement for Each Type of Motivation .21

3.2 Mean Inter-item Correlations of Motivation Subscales .24

4.1 Motivation Predicting Fanship .28

4.2 Motivation Predicting Fan Community Identification .29

4.3 Motivation Predicting Consumption of PGC Videos .30

4.4 Motivation Predicting Consumption of UGC Videos

4.5 Correlations between different types of video consumption

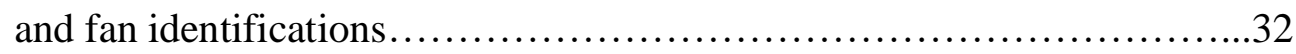

4.6 Fan Identification Predicting UGC Videos Producing Intention..........33

4.7 Consumption of Videos Predicting UGC Videos Producing Intention...34 


\section{List of Figures}

Figure $\quad$ Page

2.1 The Hypothesized Model.......................................19

5.1 A Loop of K-pop Fan Identification and Media Consumption.......... 39 


\begin{abstract}
With the easier and wider diffusion of media content from different cultures on web 2.0 platforms like YouTube, Korean Pop music has gained greater global popularity due to the emergence of participatory culture. The current study explores how global K-pop fans' consumption of UGC (user-generated content) and PGC (professional-generated content) is associated with fan motivations, identifications, and UGC creating intention. By utilizing a survey study framework and quantitative research and data gathered from K-pop fans $(\mathrm{N}=247)$ from social media, the study shows that self-esteem, group-affiliation and aesthetic were the strongest motivations of K-pop two types of fan identification (fanship and fandom) and video consumption (UGC and PGC). Fans' fanship level is more associated with their consumption of PGC whereas fan community identification level is more associated with their consumption of UGC. Both fanship level and UGC consumption have positive effects on fans' intention of creating UGC. This study provides added value for fan psychology studies in pop culture context, and also offers practical advice for entertainment companies on the leverage of PGC and UGC videos to enhance fans' psychological connection to their celebrities and communities.
\end{abstract}




\section{Chapter 1}

\section{Introduction}

Korean pop music has been gaining popularity in Asian countries for over a decade. This popularity as part of a Korean Wave, referred to as Hallyu, has spread tremendously and gained popularity in Europe, America and many other parts of the world (Kim \& Kim, 2016). For example, in 2011, views of Korean pop music videos reached 2.3 billion on YouTube in 235 countries (Min-Soo, 2012). And, BTS, a Korean boy group, recently notched its eighth total week at No. 1 on billboard Artist 100 chart followed by Bruno Mars and Lady Gaga (Zellner, 2020).

Because of the global phenomenon of K-pop, prior research attempted to understand what makes Korean pop culture so popular all over the world. One of the most important reasons identified was the influence of online social media. The wider global popularity of K-pop in recent years has been referred as "hallyu 2.0” (Lee \& Nornes, 2015), which is characterized by the essential role of social media in media production and consumption (Jung \& Shim, 2013; Oh \& Park, 2012). Global fans not only consume media content on social media platforms such as Twitter, YouTube, Facebook, and can upload and distribute content on these platforms as well. That is, with social media platforms' inherently participatory nature, both original cultural objects and the user-initiated creation of new cultural symbols and ideas related to the original object can also be disseminated (Xu et al., 2016). Online fans can gather on social media to engage, collaborate, and build relationships with celebrities and other fans, which can extend the fan base (Kim \& Kim, 2016; Gantz \& Lewis, 2014). 
Further, given the significant role that social media play in distribution of K-pop music, Oh and Park (2012) identified that the business model of Korean entertainment companies has shifted their strategy from the business-to-customers (B2C) model to the business-to-business (B2B) format. Multinational enterprises (MNEs) and Google (YouTube) are the two biggest profiteers in this K-pop value chain. Under this new business cycle that largely relies on fans' consumption and the free dissemination on Kpop videos on social media, Oh and Park pointed out that the K-pop audience on social media - non-paying customers - actually determines the fate of K-pop's business value. They also suggested that it's important to ask what content K-pop fans are looking for and why.

Based on the discussion above, this study is designed to explore the relationship between K-pop fans' self-concept (i.e., identification) and content consumption behaviors based on social identity theory and self-categorization theory, which posits that an individual's identity is constructed of a personal and a social self (Tajfel \& Turner, 1979). In addition to consuming official K-pop music videos on YouTube, fans have been creating different forms of UGC (user-generated content) related to the original music videos. To understand how different kinds of K-pop video content can enhance K-pop fan identification, this study also introduces classification of music video-related UGC (Park et al. 2014), and their different level of participatory nature.

To address research questions, this study will first introduce social identity theory and self-categorization theory which are the theoretical framework of the research. Then, by introducing two aspects of fan identification (i.e., fanship and fandom) and psychosocial factors influencing fan identification, the study will investigate how different media 
consumption behaviors and fan motivations predict these two aspects of fan identification differently. Then it reviews online fandom as a participatory culture (Jenkins, 2006) to understand the characteristics of fandom. Individual preferences for K-pop video content will be considered by examining whether different fan motivations lead to different media consumption behavior and further fan identification. Finally, because fans have been creating different forms of UGC (user-generated content) related to the original music videos, and because UGC plays an important role in creating traffic and as a free marketing approach for the K-pop industry, this study will examine how fan identification influences the intention of creating UGC. It is expected that the proposed model will demonstrate a positive feedback loop that existing inside online fan community in which consuming UGC enhance fan identification and in turn enhance UGC creation. In addition, this study will provide practical implications for entertainment companies to understand the psychological effects of different types of videos and better leverage UGC and PGC to increase fans' fanbase, fanship and fandom identification and their further fan identityrelated behaviors. 


\section{Chapter 2}

\section{Literature Review}

To provide the rationale for studying the relationship between the salience of $\mathrm{K}$ pop fan identification and their media use of UGC videos, this literature review will address social identity theory and previous fan identity studies, as well as explain the Kpop music video-related UGC on social media platforms as a kind of participatory culture.

\subsection{Social identity theory and self-categorization theory}

Social identity theory was originally formulated by Henri Tajfel and John Turner in 1979. The theory (Tajfel \& Turner, 1979) implies that individuals self-conceptualize and spontaneously categorize themselves within certain social groups. Defined by Tajfel (1987), a social identity is "that part of an individual's self-concept which derives from his knowledge of his membership of a social group together with the value and emotional significance attached to that membership" (p. 63). Moreover, self-categorization theory (Turner et al., 1987) explains "how and when people will define themselves as individual and group entities and its implications and examines the impact of this variability in selfperception ("I" to "we") for understandings of mind and behavior." (Van Lange \& Kruglanski, 2011, p.399) And, through the process of self-categorization, people form their 
own social identity. Both theories can be applied to fan cognition and behavior (Reysen \& Branscombe, 2010).

Most fan identity studies have focused on sports fans. Just as self-categorization theory suggested, sports fans have been shown to categorize themselves and others as ingroups and outgroups (Voci, 2006), they strived for maintaining positive social identity (Boen et al., 2002) and to protect their ingroups' self-esteem (Branscombe \& Wann, 1994). Fan community identification emphasizes how individuals recognize a community as "not me" or "me" and how they behave in agreement with the most salient identity (Kim \& Kim, 2017; Lam et al.,2010). For instance, sports fan identified with the team they support, and team identification unites fans as part of the in-group, providing them with solidarity and an "us versus them" atmosphere (Phua, 2010). Although more studies related to sports fans exist than pop culture fans, social identity theory has been widely used as a theoretical framework for both. While one study (Schroy et al., 2016) showed different fan communities (fantasy sports fans, anime fans, and furries) that different communities have different motivations, Reysen and Branscombe (2010) found sports fans were very similar to non-sports fans, such as those of music, media, and hobbies, and that regardless of the object of fanaticism, all fans engage in a process of identification. Reysen and Branscombe (2010) demonstrated that the term "fan" applies to "any individual who is an enthusiastic, ardent, and loyal admirer of an interest" (p. 177) and suggested previous research regarding sports fans may be generalized to fans of other interests.

Turner et al. (1994) suggested that variation of an interaction between perceiver readiness and category-stimulus fit predicts the formation and use of a social category. Perceiver readiness refers to a person's past experience, current expectations and current 
motivations, focus on goals and needs (Turner et al., 1994). Fit consists of two aspects: comparative fit and normative fit. Comparative fit refers to any collection of people more likely to be categorized into distinct groups to the degree that intragroup differences are perceived as smaller than intergroup differences within the relevant comparative context. Normative fit refers to content aspect of the match between category specifications and the instances being represented. Previous research (Oakes, 1987; Trepte \& Loy, 2017) suggest that information about in-groups and out-groups delivered by media can trigger the process of social comparison, and also, media make social categories salient.

Identity salience is the prominence and importance of a given identity in an individual's self-structure (Callero, 1985). For instance, Callero found that when blood donors' identities are more salient, they would donate blood more often, evaluate other blood donors in more extreme terms, more likely to define themselves as regular blood donors, and have more friendships linked to blood donation. Built upon social identity theory, a prior study on consumers' identity (Kleine et al., 1993) suggested that identity will be more salient when " 1 . more opportunities to enact and receive feedback about the identity (social connections), 2. more identity-relevant possessions and resources are available to enact the identity well (possessions and media connection); 3. more positive and self-enhancing feedback is received about that enactment (esteem)" (p. 226). Research also indicated that through participation in identity-related activities, role identities are realized and validated (Stryker \& Burke, 2000). For example, people may develop a more salient identity to the university as they participate in university activities more often (Arnett, 2003). These findings paved the way to explore more specific factors that can influence identity salience in fan studies. 
Reysen and Branscombe (2010) suggested that any fan communities function like any other social groups from a social identity perspective and should be studied as such. In the fan studies context, the social connection is not limited to face-to-face social interactions. Sandvoss (2005) demonstrated that fans tend to perceive themselves as members of groups even if they are not clear participants in actual fan clubs. Kashima et al. (2007) defined a relevant concept --"imagined collective" -- as a collection of individuals who interact asynchronously with each other, and who presuppose the existence of a collection of individuals with common ground. From a practical perspective, fans can seek out other fans in online communities and interact virtually (Dino, Reysen, \& Branscombe, 2009). Kleine et al. (1993) suggested that the more extensive the identity relevant media resources, such as magazines, books, newspapers, TV programs and so on that people consume, the more people can extend their knowledge of their group identity beyond the immediate social environment and know how to enact their identity. Social identity theory also supports this argument by suggesting that "individuals are driven by the quest of positive distinctiveness, media offerings become important sources of information (Trepte \& Loy, 2017, p.4)". A subsequent study on sports fans' identity salience and attendance suggested that sports marketers can enhance fans' identity salience by increasing situational involvement, enduring involvement, and attachment (Laverie \& Arnett, 2000). For example, Laverie and Arnett (2000) suggested that encouraging additional media coverage of the sports team and its players managers could enhance involvement. In addition, promotions such as contests could encourage fans to be more involved and facilitate between fans and players, which could enhance attachment. 
Consistent with the finding that media and social connection significantly predict identity salience (Kleine et al.,1993), Phua (2010)'s study on sports fan found that fans use many different forms media to find information about their fan interests. The study also suggested that media use is positively associated with fan identity and collective selfesteem, and online media has the greatest impact on an identification enhancement and collective self-esteem among four types of media (print, broadcast, online, and mobile phones) (Phua, 2010). A later study supplemented that online interaction among community members allows the members to build social ties and strengthen their trust within the community (Phua, 2012). Gantz and Lewis (2014) also illustrated that newer media are inherently interactive and share control with users, which allow sports fans to freely express themselves and extend fanship network by creating content and accessing sports content online freely.

More recent study (Kim \& Kim, 2017) focused on the K-pop online fan community had similar but more specific findings, including that social interaction, information quality, and online content established members' identification and trust and further led to a higher level of loyalty and cooperation within the community. By collecting and analyzing survey data from an online fan community of a global-renowned K-pop group, Kim and Kim demonstrated that high-quality information gave credit to the fan community, which in turn enhanced community and celebrity trust. Because negative coverage and mixed quality of information on mainstream media might have a negative influence on fans, Kim and Kim suggested entertainment management agencies place high quality of information on the top of the fan community page. Moreover, this study suggested future research should be with a greater range of multiple-dimensions of online fan community attributes, and wider and 
diverse samples of fan communities to generalize the results. As Kim and Kim stated in the study, fan community users have particular motives for media selection. For instance, if fans think that the fan community provides adequate useful information and contents about celebrities, they may spontaneously access it. It is worth noticing that user-generated content and social media play significant role in the popularity of K-pop. South Korea music company usually encourage user-generated content on social media to be part of marketing machine to monitor fans' appreciation and interpretation of K-pop music products ("What can", 2020). Therefore, studying how user-generated content to enhance K-pop fans' identification is essential for entertainment companies better leverage UGC and professionally generated content (PGC), which in turn to encourage concerts attendance, purchase, cooperation, and other K-pop fan identity-related behaviors.

In summary, previous literature concluded that when a person is exposed to media content, one or more in-groups will become salient to this person (Trepte \& Loy, 2017), media connection (Kleine et al.,1993), types of media use (Phua, 2010), and quality of media content (Kim \& Kim, 2017) all have an influence on fan identification. However, in order to better understand how current trend of participatory culture and user-generated content (will be discussed in the following sections) can be better utilized to enhance Kpop fan identification, further study on the types of media content influence on fan identification is needed to fill the gap. The next section of the literature review will summarize research into aspects of fan identity.

\subsection{Two aspects of fan identification}


Fanship and fandom are two aspects of fan identity (Reysen \& Branscombe, 2010). Fanship refers to “a person's psychological attachment to their fan interest, and fans high in fanship feel part of a distinct and positive ingroup" (Schroy et al., 2016, p.151). Fandom is a person's psychological tie to the people who share their fan interest, focusing on how being part of a fan group affects their sense of self, based on social identity theory (Schroy et al., 2016; Reysen \& Branscombe, 2010). Put another way, the difference between fanship and fandom represented in whether the fan defines the self in terms of personal attributes or in terms of membership in a social category group (Reysen \& Branscombe, 2010).

By developing the fanship scale, Reysen and Branscombe (2010) were able to assess involvement via degree of emotional connection, affiliation with other fans, and investment in the interest (e.g., money, time, energy). Through survey study, they found that fanship level is positively associated with identification with other fans (fandom) via social connection with other group members.

In a study on how Michael Jackson's fans morn his death, Courbet \& Fourquet (2014) found that fans in high fanship emphasized their personal connection to Jackson and their distinctiveness (e.g., knowledge of trivia, possessions) while mourning, whereas fandom predicted turning to other fans to share feelings while mourning. This finding suggested that fans primarily identified with their fan interest (fanship) might care less about the interaction or opinions of other fans compared to those primarily identified with fandom.

\subsection{Fan motivations}


Researchers have studied the motivations that drive sports fan activity focus on discovering unique motivations and how these motivations interact with situational and demographic variables to predict fan behavior. Wann (1995) suggested several sports fan motivators: eustress, self-esteem, escapism, entertainment, economics, aesthetics, group affiliation and family. Wann (1995)'s study also developed the Sport Fan Motivation Scale (SFMS) which later validated and used in other sports fan studies (Wann et al., 1999). This study has paved way for the later fan psychology studies. Schroy et al. (2016)'s study used Wann's SFMS to study different fan groups and found that different motivations uniquely predicted the degree of fanship and fandom, and the different fan groups differ not only in content, but also in important psychological variables. For instance, sexual attraction was a stronger predictor for the degree of fanship but not fandom for furry and anime fans, which supported the claim of Reysen and Branscombe's (2010) research that fanship and fandom are distinct constructs.

Schroy et al. (2016) demonstrated that different fan motivations predict individual differences, with implications for fan beliefs and behaviors. For instance, fans of individual sports reported higher aesthetic motivation than fans of group sports, whereas fans of group sports were more motivated by eustress and escapism (Wann, Schrader, \& Wilson, 1999). Given the difference between fanship and fandom is motivational (e.g., aesthetics and entertainment vs. group affiliation and family) (Schroy et al., 2016), it seems like different motivations predict fans' media content consumption behaviors and which in turn to predict fanship and fandom. For instance, aesthetics motivation might drive fans consume more official music videos and live performance; group affiliation motivation might encourage fans watch more UGC videos shown other fans cover K-pop fans, etc. And in 
turn enhance fans' identification with fanship and fandom differently. Schroy et al. (2016) pointed out that there has been little research studying fandom and fanship as two distinct constructs. Therefore, this study fills this gap by examining how different media consumption behavior would influence fanship and fandom differently.

As aforementioned, the use of online media positively predicts sports fan identification. Newer media and UGC (user-generated content) as essential factors in extending the K-pop fan base all over the world which will be discussed in the next section, therefore, it is necessary for this study to explore how new media, especially UGC influence K-pop fan identification.

\subsection{K-pop user-generated content and participatory culture}

The wide diffusion of social media has greatly influenced the global popularity of popular culture of the Korean Wave (Cho, 2005; Kim, 2013). A case study of online Kpop fan practice in Indonesia and the global distribution of a K-pop hit "Gangnam Style" suggest that online social networking-empowered practices are the emerging bottom-up distribution channels (Jung \& Shim, 2014). Among various international social media platforms, YouTube plays an essential role in K-pop distribution. Kim et al. (2014) demonstrated that YouTube reflects people's video consumption concentrated on K-pop music as the core of K-pop. According to Jung and Shim (2014), YouTube is considered the most desirable platform to access K-pop because global consumers are able to access to free music videos, English-subbed videos and up-to-date K-pop videos. While online 
social distribution drove the global success of K-pop, a number of scholars began to study social media, online communities, and their consumers' engagement with K-pop (Baek, 2015; Jung, 2011; Kim et al., 2014).

According to Jung and Shim (2014), the phenomenon of a K-pop hit "Gangnam Style" is the best example of the rapidity and efficiency of social media platforms. Initially published through the official channel of YG entertainment, which is based on the content partnership between YG and YouTube. Next, "Gangnam Style" was circulated among existing K-pop fan networks on various social media platforms. Then through the rise of "reaction" and parody videos on YouTube, and tweets by American celebrities, the song started to be circulated among a wider mainstream population in the global pop market. In this example, fan-made videos play great role in disseminating the song and have added further meaning to the original music video, which was an example of user-generated content. A User-generated content (UGC) is used to describe the various forms of media content that are publicly available and created by end users (Kaplan \& Haenlein, 2010). As opposed to content produced by corporations or commercial interests, UGC is considered to be created by ordinary people and uploaded online for the general public (Burgess \& Green, 2009).

K-pop fans and other active audience's online participation, such as creating content based on original materials or circulating messages reflect participatory culture. Unlike consumer culture, participatory culture is a culture in which private individuals (the public) are not just consumers but also act as contributors or producers (prosumers) (Jenkins, 2006). One of the most prolific fan studies scholars, Henry Jenkins (2006), defines participatory culture as one: 
1. With relatively low barriers to artistic expression and civic engagement

2. With strong support for creating and sharing one's creations with others

3. With some type of informal mentorship whereby what is known by the most experienced is passed along to novices

4. Where members believe that their contributions matter

5. Where members feel some degree of social connection with one another (at least they care what other people think about what they have created) (p.7).

These characteristics of participatory culture imply some features of social and media connection and participation that may influence the fan identity mentioned in the previous sections. For instance, circulation within the community shows a form of online interaction; the informal mentorship implied that fan-produced resources are relevant for a fan to learn and enact their identity. This is consistent with Otmazgin and Lyan's (2014) demonstration that social media not only plays as a medium role for individuals to get access to media information and content, but also as an organizational framework that enables community members to interact with each other and recruit new members.

Participatory culture presents an important feature of community collaboration and networking called "distributed cognition," the ability to interact meaningfully with tools that expand mental capacities (Jenkins, 2009, p.65). Jenkins believed that the emergence of digital social networks greatly changed how participatory culture operates because it allows participants who might not encounter each other otherwise to have meaningful exchanges, and to create forms of expression that flow freely and quickly within and between social networks (Jenkins, 2018). Distributed cognition not only means facility 
with technology, but also social skills that draw upon knowledge of others. Dijck (2009) also considered that emphasizing users' strong preference to share knowledge and culture in communities is the default mode of UGC platforms like YouTube. Examples of community include groups sharing a communal preference in music, movies, book or artists; anime-fans on YouTube; or even brand communities such as consumers who share the same preference of brand or follow the same diet (Dijck, 2009). Here, K-pop fandom also represents a type of participatory culture community.

As Lee and Nornes (2015) demonstrated, the K-pop industry exploits social media and actively utilizes user-generated international social networking sites like Facebook, Twitter, and YouTube to promote and disseminate K-pop. YouTube plays a special role to support participation and debate, particularly within online affinity groups like K-pop fan communities by active producers who create content and by passive users who consume, interpret, and sometimes respond to content through posting or texting (Schackman, 2008). K-pop entertainment companies not only upload professionally generated content (PGC) on the YouTube, but they also exploit UGC like K-pop flash mobs (a group of people who gather suddenly and perform K-pop dance and then quickly disperse again) videos over all over the world to identify fan communities' locations, size and other demographic information (Lee \& Nornes, 2015). These forms of UGCs allow the online circulation of offline fandom activities and elicit more offline imitation. Lee and Nornes (2015) described the current global popularity of K-pop as an example of "how both the industry producers and the consumers successfully transform themselves into equally important players in the global game of social networking" (p.85) with the emergence of media convergence of participatory culture. 


\subsection{Types of K-pop UGC videos on YouTube}

A typical scenario is that after official K-pop music videos are uploaded on YouTube by official channels of entertainment companies or record labels, a number of related UGCs such as parodies, remakes, dance, or covers start to be uploaded and circulated on YouTube. Park et al. (2014) explored the music-related UGCs by identifying a variety of trending music videos, including acoustic, cover, dance, flash mob, parody, reaction, remake, and remix. Based on Park et al.'s categorization of music video-related UGC, and found that analyzing UGCs is important to understand the popularity of the original content. Xu et al. (2016) analyzed YouTube memes and cultural diffusion by classifying producer-generated music videos and related UGC YouTube videos genres into official, original, remixing, participation and evaluation. The official category refers to videos uploaded by artists/companies' official channels; the original category refers to content uploaded by traditional mass media outlets partnering with the companies or artists; the remixing category had three subtypes -- remix, background music, and lyrics translated in different languages; the participation category included dance, parody, and cover of the original content; evaluation refers to review (evaluate the original content) and reaction videos (users' expression of opinions on the original content) (Xu, et al., 2016). (See Table 2.1)

\begin{tabular}{|l|l|l|}
\hline Genre & Genre subcategory & $\begin{array}{l}\text { Videos including content } \\
\text { about }\end{array}$ \\
\hline Official & Channel & $\begin{array}{l}\text { Clips released by official } \\
\text { channels }\end{array}$ \\
\hline
\end{tabular}




\begin{tabular}{|c|c|c|}
\hline \multirow[t]{3}{*}{ Original } & Broadcasting & $\begin{array}{l}\text { Videos promoted by } \\
\text { traditional mass media } \\
\text { outlets on YouTube }\end{array}$ \\
\hline & Concert & $\begin{array}{l}\text { Clips of public live } \\
\text { performances }\end{array}$ \\
\hline & Music video & $\begin{array}{l}\text { Official videotaped } \\
\text { performances or music } \\
\text { videos }\end{array}$ \\
\hline \multirow[t]{3}{*}{ Remixing } & Remix & $\begin{array}{l}\text { Creating a derived version } \\
\text { of original videos by } \\
\text { reassembling and re- } \\
\text { creating elements in the } \\
\text { original video }\end{array}$ \\
\hline & Background & $\begin{array}{l}\text { Videos in which the } \\
\text { original K-pop songs serve } \\
\text { as unobtrusive background } \\
\text { music }\end{array}$ \\
\hline & Lyric & $\begin{array}{l}\text { Original lyrics translated in } \\
\text { different languages }\end{array}$ \\
\hline \multirow[t]{2}{*}{ Participation } & Dance & $\begin{array}{l}\text { Clips of users moving } \\
\text { rhythmically to the K-pop } \\
\text { song in a quick and lively } \\
\text { manner; (dance cover, flash } \\
\text { mobs, dance tutorials, } \\
\text { parody dance) }\end{array}$ \\
\hline & Cover & $\begin{array}{l}\text { Singing or playing the } \\
\text { original song by using } \\
\text { various musical } \\
\text { instruments the original } \\
\text { songs }\end{array}$ \\
\hline \multirow[t]{2}{*}{ Evaluation } & Review & $\begin{array}{l}\text { Evaluating music videos/ } \\
\text { songs (formally) through a } \\
\text { critical lens }\end{array}$ \\
\hline & Reaction & $\begin{array}{l}\text { Clips of users' verbal } \\
\text { expression of opinions on } \\
\text { original video. }\end{array}$ \\
\hline
\end{tabular}

Table 2.1 Genre classification for K-pop videos on YouTube (adapted from Xu, et al., 2016, p.111)

$\mathrm{Xu}$ et al. (2016) also categorized the two most prominent types of participation of K-pop UGC on YouTube: digital creation and physical acting, which were exemplified by remix videos and dancing. They argued that physical imitation (dance videos) in UGC 
represent a higher level of participation since this imitation is an extension of digital culture to offline popular culture. Similarly, Swan (2018) also argued that visibility is central to YouTubers' participation in fandom and the relational connectivity of reaction videos. Swan called a reaction video "a communicative practice which embraces performativity and the radical expression of emotion to build sustain communities" (p.561). It is also worth noting that UGCs that are opinion-orientated such as reaction videos and reviews generally gain more concentrated audience attention and interaction (Xu et al.,2016). Identity theory posits that participation in identity-related activities is a driving force to the formation and maintenance of an identity (Stryker, 1968). This suggests that content that encourages higher participation in fandom might enhance participants' fan identity. The social identity model of media effects posits that when a person is exposed to media content, they engage in categorization, and social comparison the individual aims to gain positive distinctiveness (Trepte \& Loy, 2017). Therefore, it is logical to assume video content that featuring in-group cues/K-pop fan identity cues might have an influence on viewers fan ingroup identification.

In addition, as Li et al. (2014) suggested, "UGC creation in an online community is reciprocal among members through the interactive process of giving, receiving and repaying useful content" (p.3). As a higher level of form of participation in a community compared to passive consumption, audience's intention to create UGC has been studied. For example, Li et al. (2014) demonstrated that social capital and community support for member communication has a positive impact on members' intention to create UGC. Another study (Duan \& Dai, 2018) found that experience quality has a significant impact on user's behavioral intention of making continuous contributions. Based on these findings, 
intention to create UGC videos within K-pop community might be influenced by the frequency of consuming UGC, because consumption is a behavior that accumulate social capital within the community and the outcome of high experience quality in the community. Since community support for member communication has a positive impact on members' intention to create UGC, it is also logical to hypothesize that fan community identification is positively predict the intention of UGC creation.

In summary, user-generated social platforms in participatory culture make sharing and circulating knowledge within a network quicker and freer. Through participatory culture, members within the online community feel some degree of social connection with one another, and various types of UGC can perform as identity-relevant media resources for fans to know how to enact their identity and engage in online social interaction. This suggests that consumption on K-pop UGC videos functions as both a social and media connection that influence fan identity salience. In addition, when fans themselves physically appear in the UGC videos and share opinion (e.g., reaction, dance) which shows salient fan identity cues, the audience is more actively engaged in social comparison, which leads to a higher degree of fan in-group identification. Intention to create UGC can be predicted by both frequency of consuming K-pop videos and fan community identification.

\subsection{Research questions and hypotheses}

The hypothesized model regarding the relationship among fan motivations, types of K-pop video consumption and fan identifications are proposed (Figure 2.1): 
Figure 2.1: The Hypothesized Model

The results of this study could be valuable in the fan psychological and behavioral research by offering an aspect of pop culture. This is also helpful for explaining the recent global popularity of K-pop within participatory culture. In reference to the previous studies, several research questions and hypotheses were proposed:

RQ1: How will different fan motivations predict the level of fan identification with fanship and fandom? What are the strongest motivators of fan identification?

RQ2: How will different fan motivations predict the frequency of consumption of UGC and PGC videos? What are the strongest motivations of video consumption?

H3: The frequency of consumption of K-pop UGC videos is positively corelated with fan community identification more than fanship, and the consumption of PGC is more correlated with fanship than fan community identification. 
H4: Fanship is more positively correlated with the frequency of consumption of PGC than UGC, and fan community communication is more correlated with the consumption of UGC, especially physical appearance UGC (dance, parody, cover, reaction, review).

H5: Fan community identification (fandom) is positively associated with intention to produce UGC.

H6: The frequency of consumption of K-pop UGC videos is positively associated with intention to produce UGC.

\section{Chapter 3: Methodology}

\subsection{Procedure and Participants}


According to Wimmer \& Dominick (2013), surveys can be used to collect a large amount of data and examine many variables such as behavior, demographics, intention, attitudes, and motives, making the method a suitable instrument for this study. In addition, online surveys have the advantages of low costs, no geographic limitations, and no specific time constraints because respondents can complete the survey or measurement at their convenience (Wimmer \& Dominick, 2013). Though online surveys are known for creating convenience samples, the participants are prone to be more active. Because being active could help this research study how their motivation, behavior and fan identification influence each other, having a convenience sample is anticipated to have minor impact on the study.

The survey participants were recruited through online K-pop fan communities on mainstream social media: Twitter. K-pop fandom has become a major contributor to Twitter's growing popularity of users, which includes K-pop fans from diverse cultural backgrounds (Park, 2019). Stan Twitter is defined as a community of passionate popular culture fans on Twitter (Bellos, 2018), where fans gather and have fandom activities. Within Stan Twitter, K-pop fan communities are made based on the idol or groups they follow (Malik \& Haidar, 2020), which makes Twitter as a great platform to reach out to the sample. An online survey constructed using Qualtrics.com was posted to the active Kpop \#TwitterBestFandom category winners in 2019 (Kim, 2019) (See Appendix A). A prize draw (\$50 Amazon Gift Card) was held to encourage participation. Participants voluntarily participated by completing the online questionnaire. Considering the potential different culture background of the participants, a question asking about how difficult it is for the participants to understand the items in the survey to eliminate the data of low-quality. 422 respondents participated in the survey, after deleting the incomplete and low-quality 
answers, the sample size was 247. Participants' ages ranged between 18 70, with most (83.8\%) being 18 34. Most respondents were female $(\mathrm{N}=224)$, while only 17 were male, with 4 were non-binary/third gender. Participants were mostly Asian (N=124), while 62 were white and 10 were Black or African American.

\subsection{Variables and Measurements}

\section{Fans' motivation}

Fan motivation here are motivators that driven K-pop fans activities and behaviors. Fans' motivation will be assessed using a measure adapted from Reseysen et al. (2016) based on Wann's (1995) Sport Fan Motivation Scale. Participants rated on a scale from this is not at all descriptive of me (1) to this is very descriptive of me (7) statements based on ten potential motivators: eustress (good stress), self-esteem, escapism, entertainment, economics, aesthetics, group affiliation and family motivators identified by Wann (1995), and attention and sexual attraction, variables added by Reseyen et al. (2016). (See Appendix B). The overall reliability of the motivation scale was acceptable $(\alpha=0.841)$, however, the reliability of some of the subscales are relatively low_(see Table 3.1). In order to get better reliability of each subscale, the items that had values of corrected item-total correlation lower than 0.3 were removed (Cristobal et al., 2007). In this process, the dimension of family motivation was abandoned. It is worth noting that Nunnally (1978) recommends a minimum level of 0.7 Cronbach's Alpha values are dependent on the number of items in the scale. Considering number of the items of the subscale were only two and three, lower values Cronbach's Alpha were expected. Therefore, the mean interitem correlations of the subscales that had Alpha values below 0.7 were calculated (Table 
3.2). According to Briggs and Cheek (1986), the mean of inter-item correlations for a scale provides information about whether that scale is unidimensional or not, and the mean of inter-item correlations in the range of 0.15 to 0.50 is considered as an indicator for an acceptable level of consistency, in the case, all the values of mean of inter-item correlations were in the acceptable range. Moreover, according to Moss et al. (1998) and Hair et al. (2006), Alpha's over 0.6 are considered acceptable in social sciences studies, after abandoning data of family motivation, nine of ten dimensions of fan motivations scales were kept.

\section{Fan Motivation Type}

Escape

Eustress (good stress)

Economic

Aesthetic

Self-esteem

Group-affiliation

Entertainment

Family

Attention

Sexual attraction

Overall
Cronbach's Alpha

0.89

0.60

0.60

0.71

0.71

0.60

0.60

$\theta .42$

0.73

0.89

0.84

Table 3.1: Reliability of Measurement for Each Type of Motivation 


\begin{tabular}{ll}
\hline Fan Motivation Dimension & Mean of inter-item correlations \\
Eustress (good stress) & 0.42 \\
Economic & 0.42 \\
Group-affiliation & 0.30 \\
Entertainment & 0.34
\end{tabular}

Table 3.2 Mean Inter-item Correlations of the Motivation Subscales that Had Alpha Values Below 0.7

\section{Participants' fanship level}

Fanship here is a K-pop fan's sense of connection to a K-pop group/idol. To measure the fanship level of participants, a previously developed and tested scale (Reysen \& Branscombe, 2010) was used. The fanship scale measured behavioral involvement with the fan interest and psychological identification via the degree of emotional connection, affiliation with other fans, and fans' investments of time, money, and energy. To replicate Reysen and Branscombe (2010), the participants were asked to choose what their favorite fan interest (K-pop idol or group) is at the start, and then focused on that interest when responding to each item. Participants then completed 11 questions to evaluate their fanship, which constitute the fanship scale, rating their interests on a 7-point Likert-type scales from strongly disagree to strongly agree $(\alpha=0.84)$ (See Appendix C).

\section{Fan community identification level}

Fan community identification is the degree of an individual K-pop fan recognizes the fan community as "not me" or "me" and how they behave in agreement with the most salient identity. An organization identification scale was developed by Mael and Ashforth (1992) and later adapted to measure K-pop fan community identification by Kim and Kim 
(2011). Participants were asked to rate six items on a 7-point Likert-type scale from strongly agree to strongly disagree $(\alpha=0.77)$ (See Appendix D).

\section{The consumption of K-pop videos}

The consumption behavior of K-pop videos was operationalized as the frequency and importance of consumption of K-pop music video-related UGC, PGC (professional generated content). The classification of music video related to UGC and PCG was developed by Park et al. (2014) and later adapted by Xu et al. (2016). Twenty items asking about frequency and the importance of consumption of specific types of videos on 7-point Likert-type scale ranging from never to several times a day, and not at all important to very important were listed for participants to evaluate. The answers to questions asking about the consumption of video clips released by an official channel, videos promoted by mass media outlets, the official taped performance of music videos, and official video of public live performance were coded as frequency of consumption of K-pop PCG videos $(\alpha=0.76)$. Questions asking about the importance and frequency of consumption of the following types of videos were coded as UGC consumption $(\alpha=0.89)$ : remix videos (derived versions of original videos by reassembling and re-creating elements in the original video); background (videos in which the original K-pop songs serve as unobtrusive background music; lyrics (original lyrics translated in different languages); dance (clips of users dancing, including dance tutorials, dance parody (a humorous and exaggerated imitation of original video); covers (singing or playing the original music with various musical instruments); reviews (evaluating music videos/songs (formally) through a critical lens);

and reaction (clips of users' verbal expression of opinions on original videos). The answers to the questions asking about the consumption of dance, parody, cover, review and reaction will be coded as UGC videos with users' physical participation $(\alpha=0.88)$. After evaluating 
these statements, participants were asked to provide any types of videos they wanted a lot but didn't mention in the survey, and again, they were rated the frequency of the consumption on this type of videos, but they could skip this step.

\section{Intention to produce UGC videos}

Intention to produce UGC video means K-pop fan's willingness to continuously participate in the fan community to produce UGC videos in the future. Intention to produce UGC videos was measured on a 7-point Likert-type scale from not at all agree to agree. The item was: I intend to create any forms of K-pop UGC videos in the future.

To control confounding effects of other factors, demographic variables (age range, gender, and ethnicity) were also collected from the participants. 


\section{Chapter 4: Findings}

In order to test the hypotheses predicted in this study, several multiple regression analyses were conducted to test the relationships between fan motivations, consumption of various kinds of videos, fan identification, and UGC creating intention. Analysis I excluded all demographic variables (age range, gender, and ethnicity). Analysis $\Pi$ include the demographic information.

\subsection{Analysis I}

\section{Research Question 1.}

RQ1 explores how ten potential different kinds of motivations might predict fans' fanship level and fan community identification differently. To examine this question, firstly, a multiple regression analysis using SPSS was performed to test how fanship level was predicted based on the participants' different motivations with a confidence interval of $95 \%$, with fanship level as the dependent variable and nine types of fan motivations as independent variables. A significant regression relationship was found $(F(9,237)=17.353$, $\mathrm{p}<.01$ ), with an $\mathrm{R}^{2}$ of .397. Participants' fanship was significantly predicted by aesthetic motivation $(\beta=0.115, \mathrm{p}<0.05)$, self-esteem motivation $(\mathrm{b}=0.438, \mathrm{p}<0.001)$, and group affiliation motivation ( $\beta=0.154, \mathrm{p}<0.05$ ) as shown in Table 4.1. Comparing the values of $\beta$ for each independent variable, self-esteem was found to most strongly affected fans' fanship level among all types of motivations. In the next step, a multiple regression analysis with fan community identification scores as dependent variable, fan motivations as independent variable, was conducted to test how different fan motivations predict fans' fan 
community identification. A significant regression relationship was also found $(\mathrm{F}(9,237)$ $=17.710, \mathrm{p}<0.01)$. with an $\mathrm{R}^{2}$ of 0.402 . Participants' fan community identification was significantly predicted by their self-esteem motivation $(\beta=0.499, \mathrm{p}<0.001)$, and group affiliation motivation $(\beta=0.197, \mathrm{p}<0.01)$ as shown in Table 4.2. Self-esteem motivation was also found to be the strongest motivator of fan community identification. Therefore, the results showed that self-esteem, aesthetic and group affiliation motivations were significant and positive predictors of K-pop fan identification. By examining the standardized coefficients beta, self-esteem was most strongly associated with both fanship and fandom identification in all the motivations.

\begin{tabular}{lll|}
\hline Variable & $\beta(95 \% \mathrm{CI})$ & $P$-value \\
\hline Escape & .005 & .924 \\
Eustress & .049 & .422 \\
Economic & .063 & .329 \\
Aesthetic & .115 & $.043 *$ \\
Self-esteem & .438 & $.003^{* * *}$ \\
Group-affiliation & .154 & $.013 *$ \\
Entertainment & -.065 & .249 \\
Attention & .041 & .510 \\
Sexual attraction & .055 & .326 \\
& & \\
$\mathrm{R}^{2}$ & .397 & \\
F-value & 17.353 & \\
df & $(9,237)$ & \\
NOTE: ${ }^{*} p<.05, * * p<.01, * * * p<0.001$ &
\end{tabular}

Table 4.1 Motivation Predicting Fanship 


\begin{tabular}{|lll|}
\hline Variable & $\beta(95 \% \mathrm{CI})$ & $P$-value \\
\hline Escape & -.093 & .099 \\
Eustress & .060 & .328 \\
Economic & -.019 & .769 \\
Aesthetic & .093 & .100 \\
Self-esteem & .499 & $.000 * * *$ \\
Group-affiliation & .197 & $.002 * *$ \\
Entertainment & -.063 & .258 \\
Attention & .062 & .313 \\
Sexual attraction & -.044 & .433 \\
& & \\
$\mathrm{R}^{2}$ & .402 & \\
F-value & 17.710 & \\
df & $(9,237)$ & \\
NOTE: $* p<.05, * * p<.01, * * * p<0.001$ &
\end{tabular}

Table 4.2 Motivation Predicting Fan Community Identification

\section{Research Question 2.}

RQ2 explored how different fan motivations predict the frequency of consumption of diverse types of K-pop videos. Two multiple regression analyses were conducted to see whether different motivations predict the consumption of UGC and PGC videos differently. First, the analysis took the scores of nine motivations as independent variables, and participants' consumption on PGC video as dependent variable. A significant relationship with different fan motivations and the consumption of PGC was found: $(F(9,237)=5.601$, $\mathrm{p}<.001$ ), with an $\mathrm{R}^{2}$ of .175 . Participants' consumption of PGC video was significantly 
predicted by aesthetic motivation $(\beta=0.190, \mathrm{p}<0.01)$, self-esteem motivation $(\beta=0.238$, $\mathrm{p}<0.01)$, and sexual attraction $(\beta=0.143, \mathrm{p}<0.05)$ (Table 4.3). This result showed that self-esteem was the strongest motivator that positively predicted the frequency of consumption of K-pop PGC videos. Secondly, the regression analysis with fan motivations as independent variables and consumption of UGC videos as dependent variable was performed. Participants' UGC video consumption was also found significantly predicted by different fan motivations: $(\mathrm{F}(9,237)=8.675, \mathrm{p}<.01)$, with an $\mathrm{R}^{2}$ of .248 . Participants' consumption of UGC video was significantly predicted by economic motivation ( $\beta=0.203$, $\mathrm{p}<0.05)$, aesthetic motivation $(\beta=0.142, \mathrm{p}<0.05)$, self-esteem motivation $(\beta=0.169, \mathrm{p}<$ $0.05)$, and group-affiliation motivation $(\beta=0.146, \mathrm{p}<0.05)$ (Table 4.4). Overall, the results showed that aesthetic and self-esteem motivations positively significantly predict the consumption of PGC, and economic, aesthetic, self-esteem and group-affiliation motivations significantly positively predict the consumption of UGC.

\begin{tabular}{|lll|}
\hline Variable & $\beta(95 \% \mathrm{CI})$ & $P$-value \\
\hline Escape & .030 & .654 \\
Eustress & -.045 & .532 \\
Economic & .139 & .067 \\
Aesthetic & .190 & $.004^{* *}$ \\
Self-esteem & .238 & $.001^{* *}$ \\
Group-affiliation & .012 & .870 \\
Entertainment & -.033 & .615 \\
Attention & -.069 & .340 \\
Sexual attraction & .143 & $.030^{*}$ \\
& & \\
$\mathrm{R}^{2}$ & .175 & \\
F-value & 5.601 & \\
df & $(9,237)$ & \\
NOTE: ${ }^{*} p<.05, * * p<.01, * * * p<0.001$ & \\
\hline
\end{tabular}

Table 4.3 Motivation Predicting Consumption of PGC Videos 


\begin{tabular}{|lll|}
\hline Variable & $\beta(95 \% \mathrm{CI})$ & $P$-value \\
\hline Escape & .055 & .384 \\
Eustress & .027 & .692 \\
Economic & .203 & $.005^{* *}$ \\
Aesthetic & .142 & $.024^{*}$ \\
Self-esteem & .169 & $.013^{*}$ \\
Group-affiliation & .146 & $.035^{*}$ \\
Entertainment & .084 & .177 \\
Attention & .020 & .766 \\
Sexual attraction & .040 & .528 \\
& & \\
$\mathrm{R}^{2}$ & .248 & \\
F-value & 8.675 & \\
df & $(9,237)$ & \\
NOTE: ${ }^{*} p<.05, * * p<.01, * * * p<0.001$ & \\
\hline
\end{tabular}

Table 4.4 Motivation Predicting Consumption of UGC Videos

\section{Hypothesis 3 \& 4 .}

Hypothesis 3 predicted that the frequency of consumption of K-pop UGC videos is positively corelated with fan community identification more than fanship, and the consumption of PGC is more corelated with fanship than fan community identification. And Hypothesis 4 predicted that fanship is more positively corelated with the frequency of consumption of PGC than UGC, and fan community communication is more corelated with the consumption of UGC, especially physical appearance UGC (dance, parody, cover, reaction, review) than PGC. To examine the correlation between video consumption and 
fan identification, bivariate correlation analyses were conducted among participants' fanship level, fan community identification level, PGC, UGC, and UGC with fans' physical appearance. According to the result, participants' fanship and fan community identification was moderated associated with the consumption of PGC, UGC, and physical participation UGC ( $\mathrm{p}<0.01) . \mathrm{H} 3$ was partially supported, because the correlation between UGC consumption and participants' fanship level $(\mathrm{r}(245)=0.337, \mathrm{p}<0.01)$ is slightly greater than fan community identification level $(\mathrm{r}(245)=0.325, \mathrm{p}<0.01)$, and the consumption of PGC is more corelated with fanship ( $\mathrm{r}(245)=.369$, $\mathrm{p}<0.01$ ) than fan community identification $(\mathrm{r}(245)=.276, \mathrm{p}<0.01)$. This result has showed that the frequency of consumption of whatever kinds of videos is always more associated with fanship than fan community identification. According to the results, H4 was supported, because participants' fanship level is more correlated with the consumption of PGC $(\mathrm{r}(245)=.369, \mathrm{p}<0.01)$ than with UGC ( $\mathrm{r}(245)=.337, \mathrm{p}<0.01)$; and participants' fan community identification level is more correlated with the consumption of UGC $(\mathrm{r}(245)=.325, \mathrm{p}<0.01)$, especially with physical appearance UGC $(\mathrm{r}(245)=.337, \mathrm{p}<0.01)$ than with PGC $(\mathrm{r}(245)=.276 \mathrm{p}<0.01)$. This result shows that K-pop fans who highly identified with the fan community tend to consume more UGC videos (physical appearance videos in particular) whereas fans who have higher fanship tend to consume more PGC videos.

\begin{tabular}{|llllll|}
\hline VARIABLES & PGC & UGC & $\begin{array}{l}\text { Physical } \\
\text { Participation } \\
\text { UGC }\end{array}$ & Fanship & $\begin{array}{l}\text { Fan community } \\
\text { identification }\end{array}$ \\
\hline PGC & 1 & $.433^{* *}$ & $.396^{* *}$ & $.369^{* *}$ & $.276^{* *}$ \\
UGC & $.433^{* *}$ & 1 & $.925^{* *}$ & $.337^{* *}$ & $.325^{* *}$ \\
\hline
\end{tabular}




\begin{tabular}{|c|c|c|c|c|c|}
\hline $\begin{array}{l}\text { Physical } \\
\text { Participation UGC }\end{array}$ & $396 * *$ & $.925 * *$ & 1 & $.333 * *$ & $.337 * *$ \\
\hline Fanship & $.369 * *$ & $.337 * *$ & $.333 * *$ & 1 & $.568 * *$ \\
\hline $\begin{array}{l}\text { Fan community } \\
\text { identification }\end{array}$ & $.276^{* *}$ & $.325^{* *}$ & $.337 * *$ & $.568 * *$ & 1 \\
\hline
\end{tabular}

Table 4.5 Correlations between different types of video consumption and fan identifications

\section{Hypothesis 5}

Hypothesis 5 predicted that K-pop fans' fan community identification (fandom) is positively related with fans' intention to produce UGC. A multiple regression with participants' fanship and fan community identification as independent variables, and participants 'intention to produce UGC, was calculated. Fanship was found significantly predict participants' UGC creating intention positively $(\mathrm{F}(2,244)=10.498, \mathrm{p}<0.01),(\beta$ $=0.222, \mathrm{p}<0.01)$ but fan community identification did not. Therefore, H5 was not supported.

\begin{tabular}{|lll|}
\hline Variable & $\beta(95 \% \mathrm{CI})$ & $P$-value \\
\hline Fanship & .222 & $.003^{* *}$ \\
Fan Community Identification & .088 & .239 \\
$\mathrm{R}^{2}$ & .079 & \\
F-value & 10.498 & \\
df & $(2,244)$ & \\
NOTE: $* p<.05, * * p<.01, * * * p<0.001$ & &
\end{tabular}

Table 4.6 Fan Identification Predicting UGC Videos Producing Intention

\section{Hypothesis 6}


Hypothesis 6 predicted that the frequency of consumption of K-pop UGC videos is positively related with intention to produce UGC. A simple regression analysis with participants' consumption frequencies of UGC video as independent variable and their intention to create UGC as dependent variable was conducted. The consumption of UGC was found significantly predict participants' UGC creating intention positively $(\mathrm{F}(1,245)$ $=52.947, \beta=.422, \mathrm{p}<0.001)$, with an $\mathrm{R}^{2}$ of 0.178 . Then a multiple regression with both consumption of UGC and PGC as independent variables and UGC creating intention as dependent variable was performed. The consumption of PGC did not significantly predict participants' creating intention. Therefore, H6 was supported.

\begin{tabular}{|lll|}
\hline Variable & $\beta(95 \% \mathrm{CI})$ & $P$-value \\
\hline PGC consumption & .035 & .590 \\
UGC consumption & .407 & $.000^{* * * *}$ \\
$\mathrm{R}^{2}$ & .179 & \\
F-value & 26.543 & \\
df & $(2,244)$ & \\
\hline NOTE: $* p<.05, * * p<.01, * * * p<0.001$ & &
\end{tabular}

Table 4.7 Consumption of Videos Predicting UGC Videos Producing Intention

\subsection{Analysis II}

In analysis II, demographics variables (gender, age range, ethnicity) were entered in the analysis. The results showed that none of the demographics variables were significantly influence the above regression or correlation relationships. 


\section{Chapter 5 Conclusion and Discussion}

The present study provided new insights into the existing research in two aspects: 1.) Offering new aspects of how online videos actually influence K-pop fans psychological attributes and behaviors when most of the existing studies have identified the influential role that UGC plays in the global popularity of K-pop; 2.) Providing fan psychology studies in pop culture context when most of the fan studies have been focused on sports fans. In specific, the current study examined how UGC (user-generated content) and PGC (professional-generated content) exerted influences on K-pop fan communities' behaviors and identities.

The study demonstrated a relationship between K-pop fan identification and diverse types of video consumption. Concretely, fans' personal connection to the K-pop groups (fanship) is more positively correlated with their consumption of PGC (Professionalgenerated Content) videos; and fans' identification with fandom is more correlated with their consumption of UGC (User-generated Content), especially the UGC with fans' physical appearance (H4). This result contributed to Phua's (2010) finding that media use is positively associated with fan identity, and UGC consumption has greater impact on fan 
community identification. These results could build on the previous findings in pop music context that fanship and fan community identification are two different concepts (Reysen \& Branscome, 2010) by showing that what kinds of media affecting fans' personal connection to the K-pop stars and identification with other fans differ. The findings are also consistent with the characteristic of participatory culture that fan-produced resources are relevant for a fan to learn and enact their identity, specifically fans' physical appearance in videos which represents higher participation that reinforce the formation of an identity (Stryker, 1968; Xu et al., 2016; Otmazgin \& Lyan, 2014).

Additionally, this result that the PGC consumption is most associated with both fanship level (Table 7) indicates the sustaining control power of broadcast media and entertainment companies. This is consistent with Jenkins and Deuze (2008)'s argument that though audiences and industry both seem to be gaining and losing power, media control seems to be concentrating and dispersing in the same transitional moment, large corporations have not lost control over the communications environment, and media consumption has not totally fragmented. Despite that, it is worth noting that the more Kpop fans identified with their fandom, the more UGC videos they tend to consume, especially the physical participation UGC. This finding indicates that the consumption of UGC, especially those UGC videos with fans' self-representation, as an important fandomidentity related behavior helps maintain the community and identify a fan's identification level. From a practical perspective, on the one hand, entertainment agencies can feed various PGC content as frequently as possible in order to increase or maintain fans' psychological identification and behavioral involvement with the fan interest such as investment in their interest (e.g., money, time, energy). On the other hand, companies can 
encourage fans' participation in consumption and creation of UGC to strengthen fan community identification. Since strong fan community identification has significant effects on K-pop fans loyalty and celebrity-related product purchase (Kim \& Kim, 2017), it is helpful that companies check and locate the UGC content to better understand what kind of fan community image the fans are trying to identify with so they can distinguish themselves from the competitors.

Furthermore, another notable finding in this study is that self-esteem is the strongest predictor of fans' fanship and fandom identification (RQ1), and a strong motivator of consumption of different videos (RQ2). This result is in congruence with social identity theory that people strive to enhance their self-esteem through social comparison, which is attributed most to SIT (Tajfel \& Turner, 1979). And media could provide the information that initiate this social comparison, as Trepte et al. (2016) suggested, media use nurtures two motives: first, it plays into a person's positive social identity; second, it increases personal self-esteem arising from media use. This finding also supplements earlier fan motivation studies by revealing that different fan motivations not only predict fan identities differently (Schroy et al., 2016), but also predict fans' media consumption behaviors differently. From a practical perspective, since self-esteem is the strongest motivation of fan identification and media consumption, entertainment companies could maintain the image of the K-pop groups/stars by being proactive in coping with negative rumors and publishing high-quality positive content of their celebrities to protect their fans' self-esteem.

Noticing that $50 \%$ of the participants in this research were Asian $(\mathrm{N}=124)$, though race didn't moderate any regression relationships in the findings, nevertheless, comparing the self-esteem motivation level of participants, a significant difference was found among 
different ethnicities $(F(5,241)=2.781, \mathrm{p}<.05)$. This analysis revealed that Asian participants had higher self-esteem motivation level $(\mathrm{M}=4.59, \mathrm{sd}=1.54)$ than respondents of other races. This could explain the existing finding that K-pop serves as a form of media that functions in ethnic cohesion, cultural maintenance, and cultural integration for Asian Americans, because K-pop is a "hybridity" of the weaving of American pop culture and Asian values which Asian Americans could seek cultural closeness through (Kim, 2017; Ryoo, 2009). Asian American K-pop fans who lack sources of visibility and validation from their family and western media empower themselves by building a space to express their identity through fan productions, and by redefining racial meaning in fan-produced content while being supported and accepted by their peers in K-pop fandom communities (Choi, 2014; Yoon, 2017; Kuo et al., 2020). This finding has also shown that groupaffiliation and aesthetic motivations are other two significant predictors of fan identification and consumption of UGC videos. It is possible that K-pop stars' Asian identity, aesthetic performance, attractive personalities, or successful career satiate K-pop fans' self-esteem, aesthetic motivations. And other K-pop fans' excellent dancing cover videos or positive reactions/critiques to a music video affirm their identification with this fandom and elevate their collective self-esteem. Companies need to be actively adjusting the communication objectives of media content according to their fans' essential motivations.

The results of RQ2 suggested that economic motivation is the strongest motivators of the consumption of UGC, which was quite unexpected. Combining with the answers to open-ended question of "What other types of videos you often consume but didn't mention in the survey?" two respondents mentioned "unboxing videos of album and other 
merchandises" which belongs to one of the most popular video genres on YouTube showing people unpacking and reviewing various objects from digital phones, games and toys to audio-visual technology and beauty products (Mowlabocus, 2020). As Mowlabocus (2020) argued, the pleasure of unboxing videos articulates mobilizes our desire for commodities. Possible explanation to this finding could be that fans with potential motivation of buying or trading K-pop album or other merchandises would seek UGC videos such as unboxing videos as a way to satisfy their motivation for purchasing or trading. But a future qualitative framework research would be more helpful to provide more precise explanations.

As to fans' intention to create UGC videos, the finding has shown that fanship significantly predicts participants' UGC producing intention (H5), but fan community identification did not, which was not in line with prediction. Nonetheless, when only put fan community identification and UGC creating intention into a simple linear regression analysis, the regression was significant. Based on the finding that fanship is more associated fans' consumption of both PGC and UGC video (H3), fanship seems to play a more dominant role in fans' engaging in media consumption and creation than fandom identity. Finally, it was expected that the consumption of UGC videos significantly predict fans' intention to create UGC positively, which highlights the characteristic of participatory culture that UGC creation as a fan identity-related behavior could be a result of the informal mentorship (Jenkins, 2006).

\section{Limitations}


Despite this study provides theoretical and practical findings on K-pop fans psychology and behavior, it has some limitations. First, this study relied on only 247 valid responses. Further research could raise external validity with a greater sample size and recruiting more diverse K-pop fan communities to test the generalizability of the findings. Second, this study found some significant associations between fans' psychosocial outcomes and actual behaviors, given the correlational nature of multiple regression computation, there is no clear evidence about direction of causation. Future research could also use other compatible statistical method such as structural equation model (SEM) to better interpret causation and time order of K-pop fans' various psychological constructs and behaviors. Also, future investigations could also employ qualitative approach such as interviews to provide more insights of K-pop fans' multiple fan motivations and what causes their fanship fluctuate. Finally, fanship and fandom are two constructed originated from sports fans' studies, future study could exploring whether there are other fan concepts in pop culture context.

\section{Conclusion}

In conclusion, this study extends existing fans psychology research by revealing various significant K-pop fan motivations that predict fans' identification and actual behaviors (media consumption). In the meantime, the study contributes to the understanding of relationship between fan identification and media consumption and creating intention. Overall, the findings suggest a positive feedback loop that existing inside online K-pop fan community in which consuming UGC enhance fan identification, and high fan identification enhance UGC creation, and in turn enhance UGC consumption (Figure 5.1). 


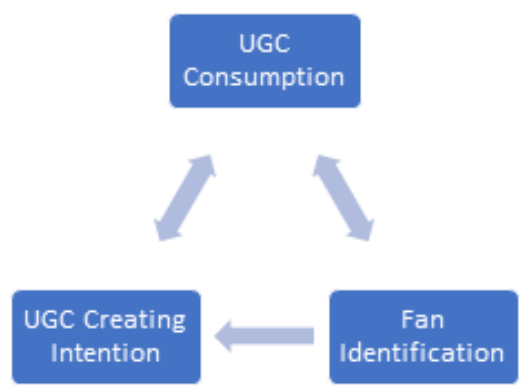

Figure 5.1: A Loop of K-pop Fan Identification and Media Consumption

Since the new social media-based business-to-business (B2B) model in Korean entertainment industry, the K-pop music industry that is now targeting royalty income from YouTube as its main source of revenue. (Oh \& Park, 2012), this study could provide helpful insights in K-pop industry marketing strategy by contributing to the understanding of UGC and PCG video in social media platforms enhance fan identification and further fan identity behaviors (such as, concert attendance, album purchase, cooperation and UGC production...).

\section{Appendix A}


Top 10 Twitter Best Fandoms ranked by total vote Tweets in 2019:

1 \#TeamEXO

2 \#TeamBTS

3 \#TeamGOT7

4 \#TeamWannaOne

5 \#TeamNCT

6 \#TeamBLACKPINK

7 \#TeamiKON

8 \#TeamStrayKids

9 \#TeamSeventeen

10 \#TeamSuperJunior

\section{Appendix B}

1. One of the main reasons that I watch, read, and/or discuss K-pop is that doing so gives me the opportunity to temporarily escape life's problems. (escape)

2. One of the main reasons that I watch, read, and/or discuss K-pop is that I get pumped up when I am watching my favorite K-pop groups. (eustress)

3. One of the main reasons that I watch, read, and/or discuss K-pop is for the artistic value. (aesthetic)

4. One of the main reasons that I watch, read, and/or discuss sports is that I enjoy the beauty and grace of K-pop music and dance. (aesthetic)

5. One of the main reasons that I watch, read, and/or discuss K-pop is that I enjoy being physiologically aroused by the K-pop content. (eustress) 
6. One of the main reasons that I watch, read, and/or discuss K-pop is that doing so makes me feel good when my favorite K-pop groups win the first place in the music charts or win awards. (self-esteem)

7. One of the main reasons that I watch, read, and/or discuss K-pop is that doing so allows me to forget about my problems. (escape)

8. Trading merchandise and making profits are the most enjoyable aspect of being a K-pop fan. (economic)

9. One of the main reasons that I watch, read, and/or discuss K-pop is because most of my friends are sports fans. (group affiliation)

10. I enjoy watching K-pop content because to me K-pop is a form of art. (aesthetic)

11. To me, watching, reading, and/or discussing K-pop is like daydreaming because it takes me away from life's hassles. (escape)

12. One of the main reasons that I watch, read, and/or discuss K-pop is I am the kind of person who likes to be with other people. (group affiliation)

13. I enjoy K-pop because of their entertainment value. (entertainment)

14. I enjoy watching K-pop videos more when I am with a large group of people. (group affiliation)

15. I enjoy watching K-pop videos because it increases my self-esteem. (selfesteem)

16. I like the stimulation I get from watching K-pop videos. (eustress)

17. I enjoy watching, reading, and/or discussing K-pop simply because it is a good time. (entertainment) 
18. To me, watching, reading, and/or discussing K-pop is simply a form of recreation. (entertainment)

19. To me, my favorite K-pop groups' successes are my successes and their losses are my losses. (self-esteem)

20. I like to watch, read, and/or discuss K-pop because doing so gives me an opportminity to be with my spouse. (family)

21. I like to watch, read, and/or discuss K-pop because doing so gives me an opporttnity to be with my family. (family)

22. I like to watch, read, and/or engage any K-pop activities because this can help me get attention from others. (Attention)

23. I like watching K-pop content is because I found the K-pop groups/idols are sexual attractive to me. (Sexual Attraction)

24. To me, being a K-pop fan helps me to get more attention which makes me feel good.

25. One of the main reasons that I watch, read or/and discuss K-pop is I'm feeling sexual attracted by the K-pop groups/idols.

26. K-pop are enjoyable only if you can bet on the outcome. (economic)

\section{Appendix C}

1) I have rescheduled my work to accommodate my favorite K-pop groups/idols.

2) I am emotionally connected to my favorite K-pop groups/idols.

3) I spend a considerable amount of money on my favorite K-pop groups/idols.

4) I do not devote much energy to my favorite K-pop groups/idols. 
5) I want everyone to know I am connected to my favorite K-pop groups/idols.

6) I would devote all my time to my favorite K-pop groups/idols if I could.

7) I would be devastated if I were told I could not pursue my favorite K-pop groups/idols.

8) I strongly identify with my favorite K-pop groups/idols.

9) When my favorite K-pop groups/idols is popular I feel great.

10) My favorite K-pop groups/idols is part of me.

11) I want to be friends with people who like my favorite K-pop groups/idols.

\section{Appendix D}

1) When someone criticizes this fan community, it feels like a personal insult.

2) I am very interested in what others think about this fan community.

3) When I talk about this fan community, I usually say "we" rather than "they."

4) I consider that the success of this fan community is my success.

5) When someone praises this fan community, it feels like a personal compliment.

6) When a story in the media criticized this fan community, I would feel

embarrassed. 


\section{Appendix E}

\section{References}

Baek, Y. M. (2015). Relationship between cultural distance and cross-cultural music video consumption on YouTube. Social Science Computer Review, 33(6), 730748.

Bellos, A, (2018, December 17) Did you solve it? Can you speak Twitter? The Guardian. https://www.theguardian.com/science/2018/dec/17/did-you-solve-it-can-youspeak-twitter

Boen, F., Vanbeselaere, N., \& Feys, J. (2002). Behavioral consequences of fluctuating group success: An Internet study of soccer-team fans. The Journal of social psychology, 142(6), 769-781.

Branscombe, N. R., \& Wann, D. L. (1994). Collective self-esteem consequences of outgroup derogation when a valued social identity is on trial. European Journal of Social Psychology, 24,641-657.

Briggs, S. R., \& Cheek, J. M. (1986). The role of factor analysis in the development and evaluation of personality scales. Journal of personality, 54(1), 106-148.

Burgess, J. E., \& Green, J. B. (2009). The entrepreneurial vlogger: Participatory culture beyond the professional-amateur divide (pp. 89-107). National Library of Sweden/Wallflower Press.

Burgess, J., and J. Green. (2009) YouTube: Online Video and Participatory Culture. Malden, MA: Polity Press.

Callero, P. L. (1985). Role-identity salience. Social psychology quarterly, 203-215. 
Cho, H. (2005). Reading the "Korean wave" as a sign of global shift. Korea Journal, $45(4)$,

consuming behaviour in different social media using K-pop videos. Journal of Information Science, 40(6), 806-822. doi:10.1177/0165551514551498

Choi, S. J. (2014). The dynamics of racial representation in the K-pop fan productions. In World Congress of Korean Studies. Manoa: University of Hawai'i.

Courbet, D., \& Fourquet-Courbet, M. P. (2014). When a celebrity dies... social identity, use of social media, and the mourning process among fans: The case of Michael Jackson. Celebrity Studies, 5, 275-290. Cultures, 8. doi:10.3983/twc.2011.0289

Cristobal, E., Flavian, C., \& Guinaliu, M. (2007). Perceived e-service quality (PeSQ). Managing service quality: An international journal.

Dawkins, R. (1976). The selfish gene. Oxford, UK: Oxford University Press. Ed.), Differentiation between social groups (pp. 61-76). London: Academic Press.

Dino, A., Reysen, S., \& Branscombe, N. R. (2009). Online interactions between group members who differ in status. Journal of Language and Social Psychology, 28(1), 85-93.

Duan, X., \& Dai, L. (2018). Study on the relationship between experience quality, Cocreated value and users' behavioral intention of making continuous contributions on internet UGC platforms. Journal of Service Science and Management, 11(02), 267.

Gantz, W., \& Lewis, N. (2014). Fanship differences between traditional and newer media. Routledge handbook of sport and new media, 19-31. 
Gilbert, B. (2019, February 11) YouTube now has over 1.8 billion users every month, within spitting distance of Facebook's 2 billion. Business Insider. https://www.businessinsider.com/youtube-user-statistics-2018-5

Hair, J. F., Black, W. C., Babin, B. J., Anderson, R. E., \& Tatham, R. L. (2006). Multivariate data analysis 6th Edition.

Jenkins, H. (2006). Fans, bloggers, and gamers: Exploring participatory culture. nyu Press.

Jenkins, H. (2018). Fandom, negotiation, and participatory culture. A companion to media fandom and fan studies, 13-26.

Jenkins, H. (2009). Confronting the challenges of participatory culture: Media education for the 21st century (p. 145). The MIT Press.

Jung, S. (2011). K-pop, Indonesian fandom, and social media| Jung| Transformative Works and Cultures. Transformative Works \& Cultures, 8.

Jung, S., \& Shim, D. (2014). Social distribution: K-pop fan practices in Indonesia and the 'Gangnam Style' phenomenon. International Journal of Cultural Studies, 17(5), 485-501.

Kaplan, A. M., \& Haenlein, M. (2010). Users of the world, unite! The challenges and opportunities of Social Media. Business horizons, 53(1), 59-68.

Kashima, Y., Klein, O., \& Clark, A. E. (2007). Grounding: Sharing Information in Social Interaction.

Kim, G. (2017). Between hybridity and hegemony in K-Pop's global popularity: A case of girls' generation's American debut. International Journal of Communication, 11(2017), 2367-2386. 
Kim, M. S., \& Kim, H. M. (2017). The effect of online fan community attributes on the loyalty and cooperation of fan community members: The moderating role of connect hours. Computers in Human Behavior, 68, 232-243.

Kim, Y. (Ed.). (2013). The Korean wave: Korean media go global. Routledge.

Kim, Y. (2019) Over 95 million \#TwitterBestFandom Tweets during the 14th Soompi Awards. BlogTwitter. https://blog.twitter.com/en_sea/topics/events/2019/Over95-million-TwitterBestFandom-Tweets-during-the-14th-Soompi-Awards.html

Kim, Y. H., Lee, D., Han, N. G., \& Song, M. (2014). Exploring characteristics of video consuming behaviour in different social media using K-pop videos. Journal of Information Science, 40(6), 806-822.

Kleine III, R. E., Kleine, S. S., \& Kernan, J. B. (1993). Mundane consumption and the self: A social-identity perspective. Journal of consumer psychology, 2(3), 209235.

Kuo, L., Perez-Garcia, S., Burke, L., Yamasaki, V., \& Le, T. (2020). Performance, Fantasy, or Narrative: LGBTQ+ Asian American Identity through Kpop Media and Fandom. Journal of Homosexuality, 1-24.

Lam, S. K., Ahearne, M., Hu, Y., \& Schillewaert, N. (2010). Resistance to brand switching when a radically new brand is introduced: A social identity theory perspective. Journal of marketing, 74(6), 128-146.

Laverie, D. A., \& Arnett, D. B. (2000). Factors affecting fan attendance: The influence of identity salience and satisfaction. Journal of leisure Research, 32(2), 225-246. 
Lee, S., \& Nornes, A. M. (Eds.). (2015). Hallyu 2.0: The Korean Wave in the age of social media. University of Michigan Press.London, England: Routledge, Taylor \& Francis Group.

Li, G., Yang, X., \& Huang, S. (2014). Effects of social capital and community support on online community members' intention to create user-generated content (Doctoral dissertation, California State University).

Mael, F., \& Ashforth, B. E. (1992). Alumni and their alma mater: A partial test of the reformulated model of organizational identification. Journal of organizational Behavior, 13(2), 103-123.

Malik, Z., \& Haidar, S. (2020). Online community development through social interaction-K-Pop stan twitter as a community of practice. Interactive Learning Environments, 1-19.

Min-Soo, S. (2012). Lessons from K-pop's Global Success. seri Quarterly, 5(3), 60.

Moss, S., Prosser, H., Costello, H., Simpson, N., Patel, P., Rowe, S., ... \& Hatton, C. (1998). Reliability and validity of the PAS-ADD Checklist for detecting psychiatric disorders in adults with intellectual disability. Journal of intellectual disability research, 42(2), 173-183.

Mowlabocus, S. (2020). 'Let's get this thing open': The pleasures of unboxing videos. European Journal of Cultural Studies, 23(4), 564-579.

Nunnally, J. C. (1978). Psychometric theory (2nd edit.) mcgraw-hill. Hillsdale, NJ, 416. 
Oakes, P. J. (1987).The salience of social categories. In J. C. Turner (Ed.), Rediscovering the social group: A self-categorization theory (pp. 117-141). Oxford, UK: Basil Blackwell.

Otmazgin, N., \& Lyan, I. (2014). Hallyu across the desert: K-pop fandom in Israel and Palestine. Cross-Currents: East Asian History and Culture Review, 3(1), 32-55.

Park, J. Y., Jang, J., Jaimes, A., Chung, C. W., \& Myaeng, S. H. (2014, April). Exploring the user-generated content (UGC) uploading behavior on youtube. In Proceedings of the 23rd International Conference on World Wide Web (pp. 529-534).

Park, S. (2019). Twitter CEO talks about K-Pop's effect on twitter and meets with GOT7's Bambam, Youngjae, and Mark. Sommpi https://www.soompi.com/article/1312094wpp/twitter-ceo-talks-about-k-popseffect-on-twitter-and-meets-withgot7s-bambam-youngjae-and-mark

Phua, J. J. (2010). Sports fans and media use: Influence on sports fan identification and collective self-esteem. International Journal of Sport Communication, 3(2), 190206.

Reysen, S., \& Branscombe, N. R. (2010). Fanship and fandom: Comparisons between sport and non-sport fans. Journal of Sport Behavior, 33(2), 176.

Reysen, S., Katzarska-Miller, I., Nesbit, S. M., \& Pierce, L. (2013). Further validation of a single-item measure of social identification. European Journal of Social Psychology, $43,463-470$.

Reysen, S., Plante, C. N., Roberts, S. E., Gerbasi, K. C., Mohebpour, I., \& Gamboa, A. (2016). Pale and geeky: Prevailing stereotypes of anime fans. The Phoenix Papers. 
Ryoo, W. (2009). Globalization, or the logic of cultural hybridization: The case of the Korean wave. Asian Journal of Communication, 19(2), 137-151. doi:10.1080/ 01292980902826427

Sandvoss, C. (2005). Fans: The mirror of consumption. Cambridge, UK: Polity Press.

Schackman, D. (2008). World fusion? Global communication about music videos on YouTube. In Proceedings from International Communication Association Annual Conference (pp. 1-37).

Schroy, C., Plante, C. N., Reysen, S., Roberts, S. E., \& Gerbasi, K. C. (2016). Different motivations as predictors of psychological connection to fan interest and fan groups in anime, furry, and fantasy sport fandoms. The Phoenix Papers, 2(2), 148-167.

Shifman, L. (2012). An anatomy of a YouTube meme. New Media \& Society, 14, 187203.

Stryker, S. (1968). Identity salience and role performance: The relevance of symbolic interaction theory for family research. Journal of Marriage and the Family, 558564.

Stryker, S., \& Burke, P. J. (2000). The past, present, and future of an identity theory. Social psychology quarterly, 284-297

Swan, A. L. (2018). Transnational identities and feeling in fandom: Place and embodiment in K-pop fan reaction videos. Communication Culture \& Critique, 11(4), 548-565.

Laverie, D. A., \& Arnett, D. B. (2000). Factors affecting fan attendance: The influence of identity salience and satisfaction. Journal of leisure Research, 32(2), 225-246. 
Tajfel, H. ( 1978). Social categorization, social identity and social comparison. In H. Tajfel

Tajfel, H., \& Turner, J. (1979). Social identity theory. dikutip dari www. learningtheories. com, diakses, 20.the social group: A self-categorization theory. Oxford: Basil Blackwell.

Trepte, S., \& Loy, L. S. (2017). Social identity theory and self-categorization theory. The international encyclopedia of media effects, 1-13.

Turner, J. C., Hogg, M. A., Oakes, P. J., Reicher, S. D., \& Wetherell, M. S. (1987). Rediscovering the social group: A self-categorization theory. Basil Blackwell.

Turner, J. C., Oakes, P. J., Haslam, S. A., \& McGarty, C. (1994). Self and collective: Cognition and social context. Personality and social psychology bulletin, 20(5), 454-463.

Van Dijck, J. (2009). Users like you? Theorizing agency in user-generated content. Media, culture \& society, 31(1), 41-58.

Van Lange, P. A., Kruglanski, A. W., \& Higgins, E. T. (2011). Handbook of theories of social psychology: Volume two (Vol. 2). SAGE publications.

Voci, A, (2006). Relevance of social categories, depersonalization and group processes: Two field studies of self-categorization theory. European Journal of Social Psychology 36,73-90.

Wann, D. L. (1995). Preliminary validation of the sport fan motivation scale. Journal of Sport and Social Issues, 19, 377-396. 
Wann, D.L., Melnick, M.J., Russell, G.W., \& Pease, D.G. (2001). Sports fans: The psychology and social impact of spectators. New York: Routledge.

Wann, D. L., Schrader, M. P., \& Wilson, A. M. (1999). Sport fan motivation: Questionnarie validation, comparisons by sport, and relationship to athletic motivation. Journal of Sport Behavior, 22(1), 114.

Wimmer, R. D., \& Dominick, J. R. (2013). Mass media research. Cengage learning. What can the global music industry learn from K-Pop and South Korea? (2020, July 13). Musically. https://musically.com/2020/07/13/what-can-the-global-music-industrylearn-from-k-pop-and-south-korea/

Xu, W. W., Park, J. Y., Kim, J. Y., \& Park, H. W. (2016). Networked cultural diffusion and creation on YouTube: An analysis of YouTube memes. Journal of Broadcasting \& Electronic Media, 60(1), 104-122.

Yoon, K. (2017). Korean Wave| Cultural Translation of K-Pop Among Asian Canadian Fans. International Journal of Communication, 11, 17. 